\title{
Utilização de nuvem privada em ambiente corporativo como estratégia para sustentabilidade nas empresas públicas
}

\author{
José Lutiano Costa da Silva ${ }^{a}$ \\ Thiago Bessa Pontes ${ }^{b}$
}

\begin{abstract}
a Mestre em Ciência da Computação pelo Centro de Informática da Universidade Federal do Pernambuco (CIN/UFPE) - Diretor Presidente do Centro de Gestão de Tecnologia da Informação - PRODAP - Amapá

b Universidade de Lisboa - Portugal. Doutorando em Tecnologias da Informação e Comunicação com ênfase em Technology Enhanced Learning and Societal Challenges pela Universidade de Lisboa. Mestre em Ciência da Computação pelo Centro de Informática da Universidade Federal de Pernambuco (UFPE). MBA em Gerenciamento de Projetos pela UniChristus. Especialista em Docência do Ensino Superior pela UNICE. Graduado em Análise e Desenvolvimento de Sistemas. Ministra aulas de Programação de Computadores para Engenharia nos cursos de Engenharia Civil e Engenharia de Materiais da Universidade Federal do Cariri (UFCA), na qualidade de professor efetivo Assistente A/DE Nível 1.

E-mail: thiago@bessapontes.com
\end{abstract}

Recebido em: 08/10/2016 I Aceito em: 02/12/2016 


\section{RESUMO}

Com o advento do uso de serviços hospedados em cenários de computação em nuvem, presencia-se a necessidade de organizações utilizarem seus benefícios. Neste âmbito, empresas governamentais possuem receio em hospedarem seus dados no ambiente em nuvem, o que por sua vez faz com que muitas dessas entidades utilizem um modelo de oferta de serviços tradicionais, não otimizados no contexto de recursos computacionais. Atualizar o modo de oferta de serviços tecnológicos é para as empresas uma forma de manter-se em competição, atendendo a fatores de sustentabilidade aos componentes ambientais e econômicos. Devido a isso, a computação em nuvem privada surge como ambiente alternativo para hospedagem de dentro da própria infraestrutura da empresa pública, suprimindo as preocupações de conformidades à segurança, adequação do modelo de oferta de serviços e do uso consciente escalável dos recursos. Com o objetivo de discutir e ampliar a literatura acerca do assunto são apresentados passos a serem utilizados para implantação de um cenário em computação em nuvem privada, como solução de problemas em uma empresa pública de processamento de dados. Como contribuição, o estudo apresenta uma solução escalável com baixo investimento, uma vez que todo o cenário proposto é utilizado em ferramental de software livre, permitindo impactos positivos e valor agregado no modelo de oferta de serviços do provedor para os clientes.

Palavras-chave: Empresa de processamento de dados; Infraestrutura como um Serviço; Cloud Computing, Tecnologia Sustentável; Sustentabilidade. 


\section{INTRODUÇÃO}

A utilização de recursos computacionais e tecnológicos em forma de serviços, desde os seus tempos mais remotos, tem destacado o uso conforme demanda sobre as necessidades dos clientes, criando assim o contexto de computação em nuvem.

O objetivo da computação em nuvem é criar um ambiente de oferta de serviços onde o cliente utiliza-os conforme a sua necessidade, podendo esta necessidade ser de: infraestrutura software, ou plataforma de desenvolvimento (este especificamente para clientes que trabalham com desenvolvimento de softwares) (ARMBRUST, 2009). Este cenário de nuvem pode se utilizar da tecnologia de virtualização como elemento básico para criar a sua infraestrutura computacional. Nessa tecnologia é possível instanciar em uma máquina física diversas máquinas virtuais que hospedarão diversos serviços, tornando-se assim um cenário otimizado e escalável de oferta de serviços conforme a demanda dos clientes.

Quando se trata no uso de servidores (Datacenters) um fator de suma importância a ser levado em questão é o do consumo de energia que ele necessita para oferecer os serviços adequadamente. Estudos recentes apontam que metade da energia usada em um datacenter vai par as cargas de TI. Já a outra metade vai para os equipamentos utilizados na infraestrutura física dos datacenters, mesmo que parte dos serviços ali disponíveis, estejam sendo subutilizados, ou até mesmo obsoletos. Considera-se também nesse consumo de energia equipamentos de alimentação, refrigeração e iluminação. Os equipamentos de refrigeração nesse caso, vitais para o funcionamento dos datacenters, parte da energia consumida é dissipada em forma de calor, que influencia diretamente na eficiência desse datacenter.

A gerência ineficaz de recursos computacionais torna-se um fator de impacto negativo para as organizações, pois nesse cenário o uso de recursos computacionais cresce bastante e pode ocorrer o não atendimento às demandas conforme necessidades de seus clientes no modelo de oferta de serviços de $\mathrm{TI}$ (Tecnologia da Informação) hospedados nessa infraestrutura computacional não otimizada, tornando assim um ambiente com problema o qual se denomina "racionalização de recursos". Os trabalhos de Andrade (2013) e Wu (2010) expõem 
esse evento de cenários computacionais que utilizam uma gerência sem otimização de recursos computacionais. Outra dificuldade que as empresas estão expostas refere-se à segurança da informação (GELLMAN, 2009).

No âmbito de empresas governamentais, estas podem realizar investimento em seus datacenters ou adequá-los, deixando de utilizarem um modelo legado e convencional de computação, onde a alocação de serviços é realizada em máquinas reais, não havendo otimização de recursos computacionais. Estas empresas podem utilizar como alternativa o modelo de computação em nuvem, em que se utiliza a técnica de virtualização para instanciar máquinas virtuais e aplicações, tornando o ambiente mais otimizado em relação a recursos e outros agregados.

O objeto de estudo deste trabalho consiste em elaborar uma proposta sustentável de implantação de computação em nuvem privada, em uma empresa pública de processamento de dados. Para isto, foram avaliados os impactos de adoção no ambiente, impactos estes incluindo modelo de oferta de serviços, utilização da virtualização, garantia de ANS (Acordo de Nível de Serviço), atendimento às demandas e necessidades das secretarias clientes da empresa de processamento de dados (provedora), análise e avaliação de riscos, análise e avaliação de componentes ambientais e econômicos, e ainda avaliar requisitos de segurança da informação em conformidade com melhores práticas de segurança da informação e segurança em computação em nuvem no processo de implementação desse cenário. Este estudo objetivou criar um cenário computacional em nuvem que otimize recursos computacionais, que potencialize o uso correto dos recursos naturais, crie um modelo de oferta de serviços de TI e garanta conformidades de segurança com as melhores práticas de segurança da informação.

\section{REFERENCIAL TEÓRICO}

A teoria do processo da destruição criadora descrita pelo autor Joseph Schumpeter no final do século XIX retrata o início do problema que hoje, no século $\mathrm{XXI}$, sofre a população do mundo inteiro no que diz respeito à produção em grande 
escala de equipamentos eletrônicos, originando muito material de descarte devido ao grande avanço das tecnologias, isso em curto período de tempo.

De acordo com a EPA (Environmental Protection Agency) os Estadounidenses descartam 2 milhões de toneladas de lixo eletrônico por ano. De acordo com o programa da ONU para o Meio Ambiente (PNUMA) o Brasil é o país que mais produz este tipo de lixo entre os países em crescimento. Segundo a revista INFO, até o final de 2011, o mundo produziu 50 milhões de toneladas de lixo eletrônico.

A monumental produção de lixo é apontada como um dos mais graves efeitos colaterais do consumismo

Trigueiro relata que

A decisão do consumidor sobre como usar e descartar os PCs tem enorme influência sobre os impactos ambientais. Prolongar a vida útil do equipamento é uma atitude bastante eficiente na redução de quase todos os tipos de problemas, mas relativamente poucos PCs antigos vêm sendo vendidos, recondicionados e reciclados (...) é preciso que o consumidor seja sensibilizado e incentivado na hora de comprar, usar e, finalmente, de se desfazer de um computador.

Este consumismo não surgiu de repente, foi planejado para tornar-se elemento de controle e disciplina social e, além de tudo, organizador cultural de comunidades, cidades e estados. Segundo Ricardo Neder (2011), desde Horkheimer e Adorno, nos anos 40, além de outros pensadores da Escola de Frankfurt já eram semeadas estas ideias.

O filosofo Herbert Marcuse: em Sociedade Tecnológica sintetiza esse consumismo desenfreado:

De fato, uma sociedade avançada, em razão do progresso tecnológico, somente se sustenta quando organiza e explora, com êxito, a produtividade da civilização industrial. A crescente produtividade de mercadorias e serviços traz consigo atitudes e hábitos prescritos, que acabam mobilizando a sociedade em seu todo, com a promessa utópica do ócio, do entretenimento e lazer organizados

O consumidor pode reduzir o descarte do lixo eletrônico utilizando seus equipamentos por mais tempo, as indústrias, entretanto já podem reduzir os desperdícios desde o início do processo de construção de um novo eletrônico. 
Parte do elixo hoje produzido se deslanchou como um início das ideias do processo da destruição criadora iniciada pelo capitalismo no fim do século XIX, o que começou a ser corrigido em meados do século $X X$ com a ideia do Sistema Toyota de Produção (STP) - empresa japonesa produtora de automóveis - ou sistema "lean" de produção, ou ainda produção enxuta, que consiste no controle para minimizar o desperdício durante a produção.

Segundo Ghinato,

O sistema Toyota de produção É uma filosofia de gerenciamento que procura otimizar a organização de forma a atender as necessidades do cliente no menor prazo possível, na mais alta qualidade e ao mais baixo custo, ao mesmo tempo em que aumenta a segurança e o moral de seus colaboradores, envolvendo e integrando não só manufatura, mas todas as partes da organização.

Entre os principais objetivos da produção enxuta destacam-se: entregas "Justin-time" (JIT), que consistem em definir que todo e qualquer processo deve ser suprido em sua quantidade certa, na fase certa, inserindo os itens adequados e necessários na quantidade e momento certo. Deve-se destacar também nesse processo que é preciso mapear e eliminar as perdas do processo, garantindo um fluxo ininterrupto na produção do insumo.

Ghinato trata do modelo just-in-time, alegando que:

É inegável que o JIT tem a surpreendente capacidade de colocar em prática o princípio da redução dos custos através da completa eliminação das perdas. Talvez, por seu impacto sobre os tradicionais métodos de gerenciamento, tenha se criado uma identidade muito forte com o próprio TPS. No entanto, o TPS não deve ser interpretado como sendo essencialmente o JIT, o que por certo limitaria sua verdadeira abrangência e potencialidade. O JIT é nada mais do que uma técnica de gestão incorporada à estrutura do TPS que, ao lado do jidoka, ocupa a posição de pilar de sustentação do sistema.

Atendendo a necessidade de reduzir o uso obsoleto de equipamentos tecnológicos, mesmo com a crescente necessidade de uso dos serviços computacionais, e ao que propõe o JIT em servir ao usuário em tempo a sua 
necessidade, e sem excessos, a computação em nuvem vem propor uma melhor solução.

A computação em nuvem traz uma nova configuração na utilização de tecnologias já conhecidas, sendo um termo genérico que pode ser definido como a evolução de tecnologias e processos, compostos de serviços, aplicações, informações e infraestrutura distribuída (MARINS, 2009).

Empresas têm investido nessa área como processos de inovação tecnológica e estratégica de negócio para seus serviços (HARRIS, 2010). O ambiente de computação em nuvem difere-se do modelo convencional de computação, baseado em aquisição de serviços e não mais em um modelo baseado em aquisição de equipamentos (MARSTON et al., 2011).

Nos dias atuais existem diversas organizações motivadas em minimizar as ameaças de segurança aos modelos de computação em nuvem, por exemplo, a Cloud Security Alliance (CSA), uma organização que surgiu no cerne destas preocupações. Outras organizações como a National Insitute of Standards and Technology (NIST), a European Network and Information Security Agency (ENISA), a OWASP Foundation com seu projeto OWASP-Cloud, e a Computer Emergency Response Team (CERT). Silva et al. (2013) apresentam um estudo sistemático sobre mapeamento de ameaças aplicadas à computação em nuvem utilizando como análise de conformidade diversas metodologias e documentações regulatórias sobre segurança em nuvem. Outro trabalho relevante sobre mapeamento de ameaças e soluções de segurança em nuvem é apresentado em Vaquero et al. (2011).

Várias tecnologias visam facilitar a vida do cidadão e a computação em nuvem é uma delas, que permite ao usuário acessar, via internet, sistemas e recursos tecnológicos sem precisarem usar os seus computadores, nem comprá-los, podendo alugá-los como serviços onde o fornecedor oferece desde infraestrutura, softwares, atualizações automáticas até o compartilhamento de arquivos, gestão e manutenção. A computação em nuvem já é realidade também no âmbito do governo federal. A Dataprev (Empresa de Tecnologia e Informações da Previdência Social), em parceria com o Serpro (Serviço Federal de Processamento de Dados), já utiliza um ambiente denominado de Expresso em Nuvem, que tem como objetivo criar um ambiente de governo padronizado para atender a demandas de correio eletrônico 
com segurança, qualidade e velocidade (DATAPREV, 2013). No que tange à segurança da informação em nuvem na esfera do governo federal, foi homologada a norma complementar no 14/IN01/DSIC/GSIPR, que estabelece diretrizes para a utilização de tecnologias de computação em nuvem, nos aspectos relacionados à Segurança da Informação e Comunicações (SIC), nos órgãos e entidades da Administração Pública Federal (APF), direta e indireta, publicada no DOU № 30 Seção 1, de 10 de fevereiro de 2012 (DSIC, 2013).

Ainda no âmbito do Governo Federal, outra empresa que está voltada para projetos de computação em nuvem é a RNP (Rede Nacional de Pesquisa), que está concebendo um projeto que vai permitir à Biblioteca Nacional e à Cinemateca oferecerem acervos digitalizados para consulta ao público. O conteúdo oferecido ainda será definido pelas instituições. Na primeira etapa de construção, o Centro de Dados Compartilhados (CDC) atenderá de forma mais restrita à comunidade acadêmica do país. A infraestrutura no início terá capacidade limitada, para que os usuários experimentem a plataforma. Entre seus objetivos estão os de abrigar grandes volumes de informações e colaborar para a manutenção/preservação de dados (FNDC, 2013).

\section{METODOLOGIA}

Este trabalho visou investigar os passos necessários e impactos da adoção em um processo de implantação de cenário de computação em nuvem privada sustentável em empresa pública de processamento de dados estadual, permitindo avaliar quais benefícios este cenário agrega referente aos quesitos de modelo de oferta de serviços, segurança da informação, e do uso consciente escalável dos recursos computacionais.

Esta investigação foi realizada fazendo um levantamento de documentações e melhores práticas que se referem à computação em nuvem e segurança da informação. Em seguida, realizou-se um diagnóstico de problemas com a infraestrutura computacional, modelo de oferta de serviço, riscos de segurança da 
informação apresentados pela empresa utilizada como objeto de estudo do trabalho, e o impacto nos componentes ambiental e econômico dessa proposta de uso consciente e sustentável dos recursos. O diagnóstico foi realizado pelos autores do trabalho e a equipe que atua com os serviços de TI referenciados neste estudo. Uma vez que trabalham na organização utilizada como objeto de estudo, e/ou realizam investigação na área de estudo. Os problemas foram identificados com uso de relatos pela equipe, em dados de maior incidência de problemas reportados na empresa.

Após esse levantamento, foi realizado um estudo em documentações técnicas que relatam soluções de computação em nuvem, solução essa que foi escolhida conforme necessidade técnica e financeira da organização, com o intuito de mitigar os problemas existentes. Em seguida, foi proposta a solução escolhida e apresentaram-se os passos utilizados para sua implantação no cenário da empresa. E por fim, foi implantado o cenário proposto e realizada uma avaliação dos impactos positivos agregados com a adoção da nuvem junto à organização utilizada como estudo deste trabalho.

Desta forma, a proposta contemplou a criação de nuvem privada em uma empresa pública que trabalha em um modelo de negócio de provedor de serviços de $\mathrm{TI}$, tendo como estudo de caso, uma entidade pública de processamento de dados. Criou-se assim, um cenário padrão para oferta de serviços de laaS e SaaS, com a finalidade de tornar-se um provedor de serviços de nuvem sustentável para as secretarias do governo público estadual, centralizando todo processamento, armazenamento, níveis de qualidade, níveis de segurança no datacenter da empresa utilizada como estudo de caso, atendendo a fatores de sustentabilidade aos componentes ambientais e econômicos. O estudo avaliou o impacto da adoção da nuvem privada para uma empresa pública de processamento de dados, e fez uma análise e avaliação de riscos comparando o cenário tradicional em nuvem privada, no processo de oferta de serviços e aspectos de segurança da informação em computação em nuvem em documentações como, NIST, CSA e a ISO 27002, já que garantir a segurança dos dados governamentais é de suma importância para empresas governamentais. 


\section{CENÁRIO DE ESTUDO}

\subsection{A realidade da empresa pública de processamento de dados}

A adoção de modelos de computação em nuvem em empresas estaduais públicas ainda é algo pouco utilizado nestas entidades. Modelos então que busquem manter um ecossistema sustentável, utilizar energias renováveis, reduzir ou reutilizar serviços de forma a otimizar recursos financeiros não se trata de uma realidade. Dado esse motivado em poucas referências disponíveis na academia e no mercado. Em discussões sobre a adoção desse modelo de serviço, principalmente na utilização de nuvem pública, muitas empresas relacionam-se com o desafio, a segurança da informação, na desconfiança se o provedor de serviços de nuvem poderá garantir a disponibilidade e integridade dos dados estratégicos da organização. Para essa problemática de hospedar dados em um provedor de nuvem pública, empresas públicas podem adotar a utilização de um modelo de oferta de serviços em sua própria infraestrutura, a nuvem privada.

\subsection{Problemas com o modelo de oferta de serviços de TI da empresa pública}

A provedora em sua infraestrutura tecnológica trabalha com ambientes convencionais, ou seja, utiliza-se de um serviço tecnológico por máquina física na maior parte de seus serviços ofertados. Com isso, torna-se oneroso o processo de administração do ambiente para a equipe de TI, uma vez que a quantidade de equipamentos físicos é grande. Outro ponto é o não uso dos recursos computacionais de forma otimizada, em alguns casos muitas máquinas subutilizadas. O consumo elétrico também se torna um problema financeiro, uma vez que quanto mais se utiliza equipamentos, maior será o consumo elétrico. 
Os dez problemas mais específicos e principais com o ambiente da provedora são:

1. Não otimização de recursos (racionalização);

2. Problemas com versões de aplicações de teste e produção;

3. Não atendimento às necessidades de requisições de softwares demandados pelas secretarias;

4. Demora no processo de implementação de ambiente para produção sob demanda;

5. Gerenciamento não centralizado dos servidores;

6. Probabilidade de risco maior em caso de incidentes de segurança física;

7. Dificuldade de garantir a disponibilidade com redundância dos servidores;

8. Gerenciamento do ambiente mais complexo;

9. Maior dificuldade para escalabilidade de recursos computacionais;

10. Maior dificuldade em deixar o ambiente computacional em conformidade com normas de segurança;

Os quadros 1, 2 e 3 apresentam informações a respeito da utilização de recursos computacionais na provedora.

Quadro 1 - Consumo de processamento em servidores físicos da provedora.

\begin{tabular}{|c|l|l|c|c|}
\hline ID & \multicolumn{1}{|c|}{ Servidor } & \multicolumn{1}{|c|}{ Descrição } & $\begin{array}{c}\text { Quantidade de } \\
\text { Processadores }\end{array}$ & $\begin{array}{c}\% \text { de } \\
\text { utilização }\end{array}$ \\
\hline 1 & Web & $\begin{array}{l}\text { Servidor que faz a } \\
\text { hospedagem dos sites da } \\
\text { provedora e clientes }\end{array}$ & 4 & $70 \%$ \\
\hline 2 & Webmail & $\begin{array}{l}\text { Servidor de webmail que } \\
\text { atende a todas as } \\
\text { secretarias de Estado }\end{array}$ & 4 & $50 \%$ \\
\hline 3 & $\begin{array}{l}\text { Aplicações WEB } \\
\text { PHP }\end{array}$ & $\begin{array}{l}\text { Servidor com aplicações } \\
\text { Web desenvolvidas em } \\
\text { PHP }\end{array}$ & 2 & $75 \%$ \\
\hline Aplicações WEB & $\begin{array}{l}\text { Aplicações Web } \\
\text { desenvolvidas em } \\
\text { linguagem de } \\
\text { programação Ruby }\end{array}$ & $\begin{array}{l}\text { Aplicações Web em Java } \\
\text { Java }\end{array}$ & 2 & $72 \%$ \\
\hline
\end{tabular}


Utilização de nuvem privada em ambiente corporativo como estratégia para sustentabilidade nas empresas públicas

\begin{tabular}{|c|l|l|c|c|}
\hline 6 & Aplicações WEB EaD & Sistema de EaD & 4 & $45 \%$ \\
\hline 7 & $\begin{array}{l}\text { Aplicação de } \\
\text { empréstimos }\end{array}$ & $\begin{array}{l}\text { Servidor que hospeda o } \\
\text { sistema de empréstimos } \\
\text { financeiros }\end{array}$ & $45 \%$ \\
\hline 8 & $\begin{array}{l}\text { Aplicação de } \\
\text { segurança pública }\end{array}$ & $\begin{array}{l}\text { Servidor que hospeda o } \\
\text { sistema de segurança } \\
\text { pública }\end{array}$ & $40 \%$ \\
\hline 9 & $\begin{array}{l}\text { Aplicação de } \\
\text { Impressão }\end{array}$ & $\begin{array}{l}\text { Servidor que realiza o } \\
\text { processo de impressão } \\
\text { corporativo }\end{array}$ & $60 \%$ \\
\hline 10 & $\begin{array}{l}\text { Aplicação Filtro de e- } \\
\text { mail }\end{array}$ & $\begin{array}{l}\text { Aplicação de processo de } \\
\text { filtragem de AntiSpam / } \\
\text { Antivírus para e-mail }\end{array}$ & 2 & $60 \%$ \\
\hline Capacidade total de quantitativo de processadores & $\mathbf{2 7}$ & $\mathbf{5 8 . 2 \%}$ \\
\hline \multicolumn{2}{|c|}{ Média de Consumo Total de todos Servidores de Processamento } \\
\hline
\end{tabular}

Fonte: o autor.

Quadro 2 - Consumo de memória RAM em servidores da provedora.

\begin{tabular}{|c|l|c|c|}
\hline \multirow{2}{*}{ ID } & \multicolumn{1}{|c|}{ Servidor } & Quantidade RAM & $\%$ utilização \\
\hline 1 & Web & $12 \mathrm{~GB}$ & $80 \%$ \\
\hline 2 & Webmail & $12 \mathrm{~GB}$ & $60 \%$ \\
\hline 3 & Aplicações WEB PHP & $24 \mathrm{~GB}$ & $65 \%$ \\
\hline 4 & Aplicações WEB Ruby & $24 \mathrm{~GB}$ & $55 \%$ \\
\hline 5 & Aplicações WEB Java & $24 \mathrm{~GB}$ & $75 \%$ \\
\hline 6 & Aplicações WEB EaD & $8 \mathrm{~GB}$ & $40 \%$ \\
\hline 7 & Aplicação de empréstimos & $12 \mathrm{~GB}$ & $70 \%$ \\
\hline 8 & Aplicação de segurança pública & $24 \mathrm{~GB}$ & $40 \%$ \\
\hline 9 & Aplicação de Impressão & $8 \mathrm{~GB}$ & $65 \%$ \\
\hline 10 & Aplicação Filtro de e-mail & $12 \mathrm{~GB}$ & $50 \%$ \\
\hline
\end{tabular}




\begin{tabular}{|l|c|}
\hline Capacidade total de memória & \multirow{3}{*}{60 GB } \\
\cline { 1 - 2 } Média de Consumo Total de todos Servidores de RAM & \\
\hline
\end{tabular}

Fonte: o autor.

Quadro 3 - Consumo de Armazenamento em servidores físicos da provedora

\begin{tabular}{|c|c|c|c|}
\hline ID & Servidor & Armazenamento & \% utilização \\
\hline 1 & Web & $250 \mathrm{~GB}$ & $28 \%$ \\
\hline 2 & Webmail & $250 \mathrm{~GB}$ & $55 \%$ \\
\hline 3 & Aplicações WEB PHP & $500 \mathrm{~GB}$ & $23 \%$ \\
\hline 4 & Aplicações WEB Ruby & $250 \mathrm{~GB}$ & $25 \%$ \\
\hline 5 & Aplicações WEB Java & $250 \mathrm{~GB}$ & $29 \%$ \\
\hline 6 & Aplicações WEB EaD & $500 \mathrm{~GB}$ & $15 \%$ \\
\hline 7 & Aplicação de empréstimos & $300 \mathrm{~GB}$ & $35 \%$ \\
\hline 8 & Aplicação de segurança pública & $300 \mathrm{~GB}$ & $28 \%$ \\
\hline 9 & Aplicação de Impressão & $250 \mathrm{~GB}$ & $18 \%$ \\
\hline 10 & Aplicação Filtro de e-mail & $500 \mathrm{~GB}$ & $23 \%$ \\
\hline \multicolumn{2}{|r|}{ Capacidade total de armazenamento } & 3.3 TB & \multirow[b]{2}{*}{$27.9 \%$} \\
\hline \multicolumn{3}{|c|}{ Média de Consumo de Armazenamento Total de todos os } & \\
\hline
\end{tabular}

Fonte: o autor.

Para mostrar a subutilização de recursos computacionais, especificamente processamento, consumo de memória e armazenamento, este trabalho realizou coleta de dados sobre os recursos utilizando uma ferramenta de monitoramento de recursos em servidores no período do mês de novembro de 2012 (entre os dias 05 a 30 mês), essa coleta foi realizada utilizando o protocolo SNMP, onde cada máquina 
que provia serviços na provedora foi instalada um cliente, que enviava as informações dos recursos para uma máquina servidora com a ferramenta Cacti. Ferramenta de fácil instalação e configuração, por isso a escolha. A ferramenta realiza a coleta dos dados em um intervalo de 30 segundos, soma os resultados para realizar a média de consumo dos recursos em caso da necessidade de se gerar um relatório. A coleta considerou apenas o horário comercial de trabalho.

O quadro 1 ilustrou o resultado do consumo em recursos referente ao processamento de equipamentos da provedora. O quadro 2 apresenta os resultados do consumo de memória RAM, e por fim, o quadro 3 ilustra a mal racionalização de recursos sobre o armazenamento de dados.

A média de consumo entre todos os servidores ilustrados no quadro 1 está abaixo de $60 \%$ da capacidade total de processamento, ou seja, servidores subutilizados e não racionalizados. O consumo de memória RAM na infraestrutura de servidores não ultrapassou $70 \%$. No que tange ao consumo de armazenamento contemplando toda a estrutura, nota-se que não há um consumo de $30 \%$ da sua capacidade total.

Outro fator para justificar a adoção da computação em nuvem está diretamente ligado à técnica de consolidação de servidores com a tecnologia de virtualização que é a redução de consumo de energia. A consolidação de servidores é uma reestruturação da infraestrutura de uma organização para fins de redução de custos e melhoria do controle pela otimização dos requisitos de recursos.

Para medir o consumo de energia no ambiente utilizou-se a potência da fonte das máquinas apresentadas no cenário de estudo da provedora. O cálculo do consumo foi realizado da seguinte forma: Consumo de energia da fonte = potência da fonte versus número de fontes do total de servidores. Em seguida mediu-se o consumo diário na seguinte maneira: Consumo diário de energia da fonte = Consumo diário de energia da fonte versus número total de horas no dia dividido por 1.000 (para transformar em uma medida de potência maior de Watt para Kilowatt). E por fim, mediu-se o consumo mensal, onde tem-se: Consumo mensal de energia da fonte $=$ consumo diário de energia da fonte versus 30 . As informações do cenário 
são de fonte com potência de 670 watts, num total de 20 unidades, por um tempo de funcionamento de 24 horas.

Os dados acima foram sobre o cenário legado da provedora que subsidiaram o cálculo de consumo de energia, cujo cálculo foi o de consumo diário de 670 vezes 20 = 13.400 watts. Sabendo que o funcionamento está em 24 horas temos o consumo diário em 321.600 watts (13.400 vezes 24 ), o que gera um consumo diário de 321,6 Kw por dia (321.600 por 1000). Dessa forma o consumo mensal estimou-se em 9.468 kw/mês (321,6 vezes 30).

Acima se tem os dados que mostram o consumo de energia do cenário legado da provedora antes da implantação da proposta. Essas Métricas são usadas para ilustrar uma visão quantitativa sobre o consumo de energia.

\section{PROPOSTA DE SOLUÇÃO DE COMPUTAÇÃO EM NUVEM PARA A PROVEDORA}

A proposta de solução em nuvem privada da provedora contemplou a escolha de tecnologias e ferramentas que atendam às necessidades do ambiente $\mathrm{e}$ consigam oportunizar a solução dos problemas relatados. Nesse âmbito, a escolha da ferramenta foi em software livre, pois se tratando de uma empresa pública com as particularidades como as dela, torna-se uma alternativa quando se necessita de investimento em soluções licenciadas. Ainda nesse raciocínio, é a maturidade de soluções livres existentes no mercado, e o uso por outras empresas, como do governo federal que já atuam com soluções desse nicho.

\subsection{Fases do projeto de solução em nuvem para a provedor}

Para este trabalho, foi proposta uma solução de computação em nuvem privada para a provedora contemplando conformidades com normas, melhores práticas de segurança da informação de forma a otimizar os recursos tornando o serviço mais sustentável. Onde foi fundamentada conforme as fases do ciclo de vida de projeto. As fases foram definidas de acordo com o modelo de gerenciamento de 
projetos definido no guia de boas práticas (Project Management Body of Knowledge - PMBOK) do PMI (Project Management Institute) conforme a figura 1.

Figura 1 - Grupo de Processos segundo PMBOK ( adaptado de Guia PMBOK® - Project Management Body of Knowledge, 2016).

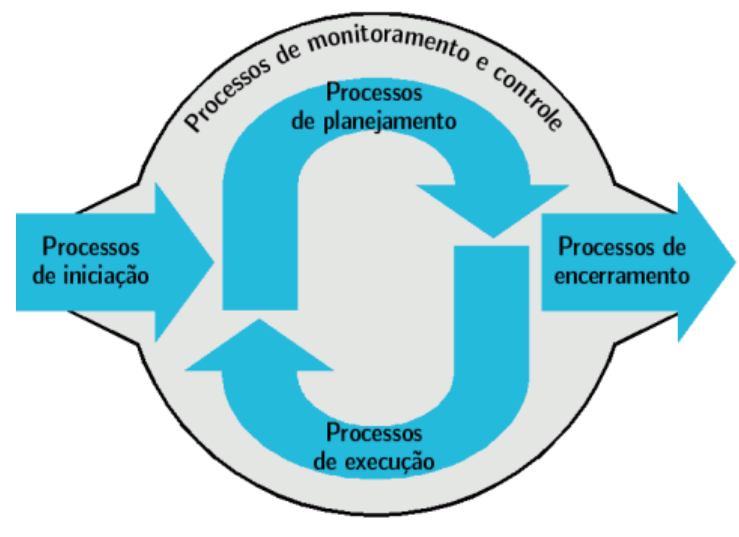

Inicialização da proposta: Esta fase teve como objetivo apresentar a justificativa da existência e necessidade de realizou-se um projeto de computação em nuvem para a provedora. 
Nessa fase foram mapeadas algumas atividades como as quais:

i. Identificação de problemas com o ambiente computacional existente da provedora em relação a serviços de Tl;

ii. Objetivar proposta;

iii. Justificar proposta; Ter autorização da gestão para prosseguir com a proposta;

Planejamento da proposta: Nesta o objetivo foi planejar o fluxo de atividades que compõem o processo de implantação da proposta As atividades vinculadas a esta fase são:

i. Definir escopo do projeto;

ii. Definir modelo de serviço ofertado;

iii. Definir recursos tecnológicos necessários;

iv. Definir planejamento de estimativa de tempo para execução da proposta;

v. Definir estimativa de riscos para a execução da proposta: Nesta atividade, foi definido e utilizado o método avaliativo adaptado de Ramos (2006) para a análise e avaliação de riscos na proposta. A figura 2 ilustra o método utilizado.

Figura 2 - Método de análise e avaliação de riscos (adaptado de Ramos, 2006)

\begin{tabular}{|c|c|}
\hline Risco Baixo & De 1 a 6 \\
\hline Risco Médio & De 7 a 12 \\
\hline Risco Alto & De 13 a 27 \\
\hline
\end{tabular}

\begin{tabular}{|c|c|c|c|}
\hline Níveis & Alto & Médio & Baixo \\
\hline Valores & 3 & 2 & 1 \\
\hline Risco & $=$ Vulnerabilidade $\mathrm{x}$ Ameaça $\mathrm{x}$ \\
Impacto
\end{tabular}

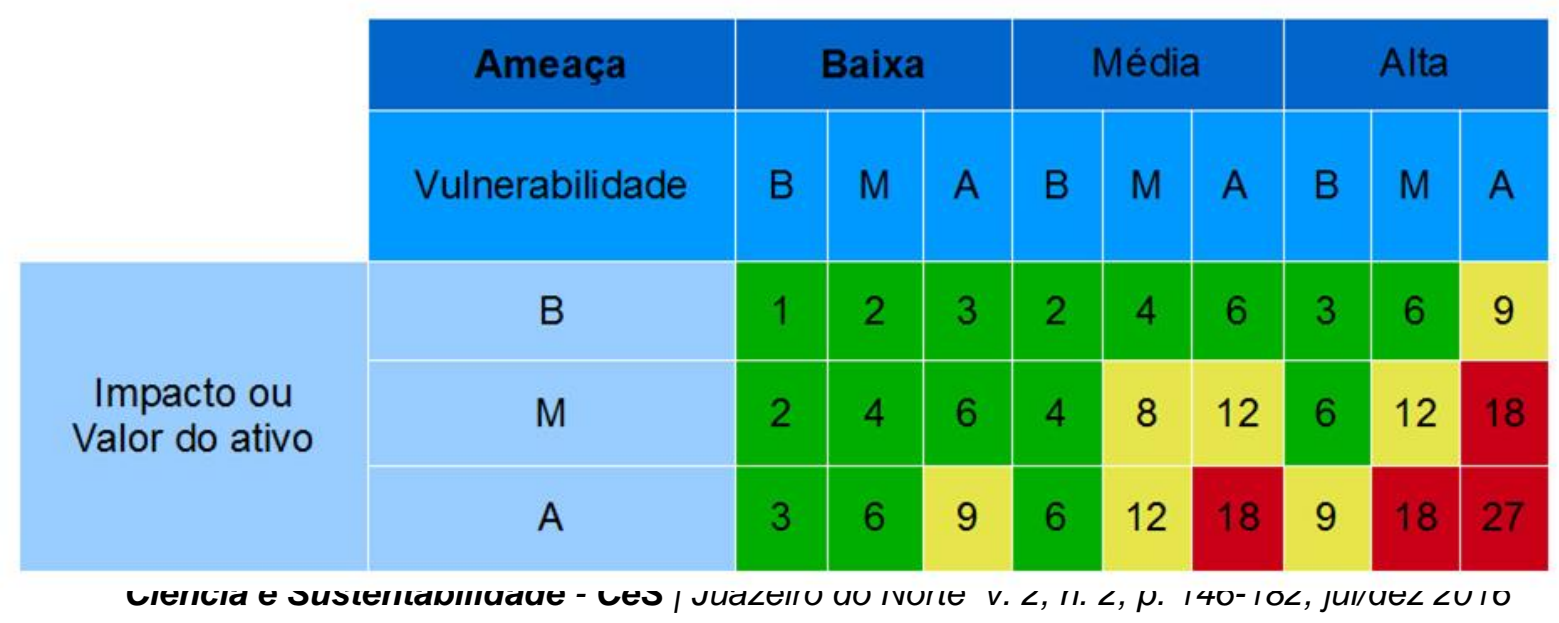


Quadro 4 - Processo de análise e avaliação de risco na provedora.

\begin{tabular}{|c|c|c|c|c|c|}
\hline ID & Ativo & Ameaça & Vulnerabilidade & Impacto & Risco \\
\hline 1 & $\begin{array}{l}\text { Otimização de } \\
\text { Recursos } \\
\text { Computacionais }\end{array}$ & $\begin{array}{l}\text { - Alta demanda de } \\
\text { implementação de } \\
\text { serviços e falta de } \\
\text { racionalização (2) }\end{array}$ & $\begin{array}{l}\text { - Não } \\
\text { racionalização de } \\
\text { recursos } \\
\text { - Profissionais } \\
\text { terem a visão de } \\
\text { otimização } \\
\text { eficiente (2) }\end{array}$ & $\begin{array}{l}\text { MÉDIO } \\
\text { (2) }\end{array}$ & $\begin{array}{l}\text { MÉDIO } \\
\text { (8) }\end{array}$ \\
\hline 2 & $\begin{array}{l}\text { Garantia de } \\
\text { Versionamento } \\
\text { de ambientes }\end{array}$ & $\begin{array}{l}\text { - Equipe de } \\
\text { desenvolvimento } \\
\text { utilizar ambiente não } \\
\text { alinhado } \\
\text { com a produção (2) }\end{array}$ & $\begin{array}{l}\text { - Indisponibilidade } \\
\text { de recursos para o } \\
\text { ambiente de } \\
\text { desenvolvimento e } \\
\text { produção (2) }\end{array}$ & $\begin{array}{l}\text { ALTO } \\
\text { (3) }\end{array}$ & $\begin{array}{l}\text { MÉDIO } \\
\text { (12) }\end{array}$ \\
\hline 3 & $\begin{array}{l}\text { Atendimento as } \\
\text { necessidades das } \\
\text { Secretarias }\end{array}$ & $\begin{array}{l}\text { - Falta de recursos } \\
\text { computacionais (2) }\end{array}$ & $\begin{array}{l}\text { - Não utilização de } \\
\text { otimização de } \\
\text { recursos (1) }\end{array}$ & $\begin{array}{l}\text { MÉDIO } \\
\text { (2) }\end{array}$ & $\begin{array}{l}\text { BAIXO } \\
\quad(4)\end{array}$ \\
\hline 4 & $\begin{array}{l}\text { Demora na } \\
\text { Implementação de } \\
\text { ambiente }\end{array}$ & $\begin{array}{l}\text { - Falta de recursos } \\
\text { computacionais (2) }\end{array}$ & $\begin{array}{l}\text { - Não utilização de } \\
\text { otimização de } \\
\text { recursos (2) }\end{array}$ & $\begin{array}{l}\text { MÉDIO } \\
\text { (2) }\end{array}$ & $\begin{array}{l}\text { MÉDIO } \\
\text { (8) }\end{array}$ \\
\hline 5 & $\begin{array}{l}\text { Gerenciamento } \\
\text { descentralizado }\end{array}$ & $\begin{array}{l}\text { - Profissionais não } \\
\text { realizarem } \\
\text { configurações } \\
\text { necessárias em } \\
\text { todos servidores (2) }\end{array}$ & $\begin{array}{l}\text { - Não utilização de } \\
\text { ambiente } \\
\text { centralizado e } \\
\text { solução } \\
\text { centralizada para } \\
\text { configurações (2) }\end{array}$ & $\begin{array}{l}\text { ALTO } \\
\text { (3) }\end{array}$ & $\begin{array}{l}\text { MÉDIO } \\
(12)\end{array}$ \\
\hline 6 & Segurança Física & $\begin{array}{l}\text { - Problemas } \\
\text { elétricos } \\
\text { - Queima de } \\
\text { equipamentos (1) }\end{array}$ & $\begin{array}{l}\text { - Não utilização de } \\
\text { solução de } \\
\text { redundância (2) }\end{array}$ & $\begin{array}{l}\text { ALTO } \\
\text { (3) }\end{array}$ & $\begin{array}{l}\text { BAIXO } \\
\quad(6)\end{array}$ \\
\hline 7 & $\begin{array}{l}\text { Garantir a } \\
\text { Disponibilidade }\end{array}$ & $\begin{array}{l}\text { - Queima de } \\
\text { equipamentos } \\
\text { - Queda de serviços } \\
\text { (1) }\end{array}$ & $\begin{array}{l}\text { - Não utilização de } \\
\text { solução de } \\
\text { redundância (2) }\end{array}$ & $\begin{array}{l}\text { MÉDIO } \\
\text { (2) }\end{array}$ & $\begin{array}{l}\text { BAIXO } \\
(6)\end{array}$ \\
\hline 8 & $\begin{array}{l}\text { Gerenciamento } \\
\text { complexo }\end{array}$ & $\begin{array}{l}\text { - Demanda alta para } \\
\text { os profissionais (2) }\end{array}$ & $\begin{array}{l}\text { - Não utilização de } \\
\text { ambiente } \\
\text { centralizado e } \\
\text { solução } \\
\text { centralizada para } \\
\text { configurações (2) }\end{array}$ & $\begin{array}{l}\text { MÉDIO } \\
(2)\end{array}$ & $\begin{array}{l}\text { MÉDIO } \\
\text { (8) }\end{array}$ \\
\hline 9 & $\begin{array}{l}\text { Dificuldade para } \\
\text { escalabilidade }\end{array}$ & $\begin{array}{l}\text { - Poucas máquinas } \\
\text { físicas (1) }\end{array}$ & $\begin{array}{l}\text { - Não otimização } \\
\text { de recursos } \\
\text { computacionais } \\
\text { (2) }\end{array}$ & $\begin{array}{l}\text { ALTO } \\
(3)\end{array}$ & $\begin{array}{l}\text { BAIXO } \\
(12)\end{array}$ \\
\hline 10 & $\begin{array}{l}\text { Dificuldade em } \\
\text { realizar } \\
\text { conformidade com }\end{array}$ & $\begin{array}{l}\text { - Ambiente } \\
\text { complexo } \\
\text { - Alta demanda para } \\
\end{array}$ & $\begin{array}{l}\text { - Não utilização de } \\
\text { um ambiente } \\
\text { otimizado }\end{array}$ & $\begin{array}{l}\text { MÉDIO } \\
\text { (2) }\end{array}$ & $\begin{array}{l}\text { MÉDIO } \\
\text { (8) }\end{array}$ \\
\hline
\end{tabular}




\begin{tabular}{|c|c|c|}
\hline $\begin{array}{l}\text { segurança da } \\
\text { informação }\end{array}$ & $\begin{array}{l}\text { os profissionais e } \\
\text { falta de tempo para } \\
\text { avaliar o ambiente } \\
\text { em conformidades } \\
\text { (2) }\end{array}$ & $\begin{array}{l}\text { - Não aderência a } \\
\text { metodologias, } \\
\text { melhores práticas } \\
\text { e normas de } \\
\text { segurança da } \\
\text { informação (2) }\end{array}$ \\
\hline
\end{tabular}

Fonte: 0 autor.

O método de análise e avaliação de risco, descrito na Figura 2, teve como intuito calcular o risco, que é medido através de três variáveis: ameaça, vulnerabilidade e impacto. A ameaça é o que pode gerar um incidente para o ativo da informação (elemento utilizado no processo, por exemplo, banco de dados), a vulnerabilidade é a ausência de algum mecanismo de proteção ou proteção ineficaz e, por fim, o impacto é a ação da ameaça sobre a vulnerabilidade.

O quadro 4 ilustrou o processo de análise e avaliação de risco nos elementos (problemas) descritos neste estudo, nesse processo foram apresentados os riscos antes da proposta de computação em nuvem privada para a provedora. Com isso, a proposta desse trabalho foi mitigar todos os riscos mostrados na referida tabela.

- Alinhar proposta com normas, metodologias que se relacionam à computação em nuvem, gerência e segurança da informação;

- Execução da proposta: O objetivo desta fase foi executar todas as atividades que foram definidas na fase de planejamento da proposta.

- Monitoração da proposta: Esta fase foi realizada desde o início do projeto, ou seja, trabalha de forma paralela às demais, pois nela ocorre a monitoração das atividades realizadas e gerência, possíveis mudanças no fluxo do projeto para adequá-lo a melhor maneira de garantir o que foi proposto no início do projeto.

- Encerramento da proposta: E por fim, a última fase do ciclo realiza o encerramento do projeto, esse artefato foi feito com a entrega da documentação final de todo projeto, contemplando tempo, custo, níveis de qualidade, níveis de segurança supostamente atingidos com a implantação da proposta. 


\subsection{Tecnologias utilizadas na proposta de nuvem privada para provedora}

As tecnologias utilizadas na proposta de nuvem privada para a provedora são todas de padrão aberto, e a justificativa da escolha decorre devido aos custos monetários. Caso fosse escolhida uma solução proprietária, muitos órgãos públicos não dispõem de recursos financeiros para implementações deste tipo de projeto.

\subsection{Ferramentas utilizadas na proposta}

As ferramentas utilizadas para a criação do ambiente de nuvem privada foram todas em software livre, fomentando assim a redução de custos com licenciamento de softwares proprietários. A escolha das ferramentas em software livre deu-se pelo fato da tecnologia base para a criação do ambiente de nuvem ser a virtualização, e no mercado duas soluções, são mais difundidas, a XEN e VMWARE. Assim, comparando as características técnicas e atentando-se ao escopo da proposta deste estudo, conforme Lowe (2008) que trata sobre as características da VMWARE e Mathews (2009) da XEN, notou-se que no quesito de características e investimentos financeiros, a solução XEN atenderia aos requisitos da proposta.

Este trabalho propõe o uso de ferramentas em software livre que não são particulares para o uso em um modelo de computação em nuvem. Um modelo computacional tradicional poderia também utilizar-se de tais ferramentas, entretanto, a proposta é utilizar essas ferramentas para tornar o ambiente mais racionalizado em um cenário de computação em nuvem privada. As ferramentas utilizadas nesta proposta são: XCP; Apache; PHP; GNU/Linux; MySQL; OpenSSH; Tomcat; Joomla; Wordpress; QMAIL; Zabbix; Puppet; FreeNAS;

\subsection{Recursos computacionais utilizados na proposta}


Para validar a proposta deste trabalho, a solução de nuvem privada utilizou-se de 4 máquinas servidoras, sendo 2 utilizadas para o ambiente de aplicações e 2 para armazenamento das VMs, além da utilização de um equipamento concentrador, o switch, para interligar os servidores em redes de computadores.

As configurações dos servidores de aplicação são:

- 4 Processadores: CPU: Intel(R) Xeon(R) CPU - E5320@ 1.86GHz

- 64 GB de memória RAM

- 300 GB de disco

- 4 Interfaces de Rede GigabitEthernet

As configurações dos servidores de armazenamento são as mesmas dos servidores de aplicação, mas diferem-se no tamanho do disco e na quantidade de memória, elas são:

- 4 Processadores: CPU: Intel(R) Xeon(R) CPU - E5320@ $1.86 \mathrm{GHz}$

- 32 GB de memória RAM

- 1 TB de disco

- 4 Interfaces de Rede GigabitEthernet

\section{IMPLEMENTAÇÃO DE SOLUÇÃO SUSTENTÁVEL DE NUVEM PRIVADA PARA A PROVEDORA}

O cenário implementado de nuvem privada para a provedora é contemplado com ferramentas livres e tecnologias de padrões abertos. O cenário foi provido com a ferramenta XCP, que se utilizou da virtualização e outras tecnologias como DMC (Dynamic Memory Control). Esta tecnologia foi um fator importante para o processo de oferta de serviços na nuvem, fazendo-se assim o cliente ter a visão de recursos altamente escaláveis (VERAS, 2012).

A garantia de monitoração da disponibilidade dos serviços da nuvem utiliza a ferramenta Zabbix para gerenciar recursos do ambiente como: processamento, capacidade de disco, disponibilidade dos serviços, memória, tráfego de rede, número de conexões nas aplicações providas. Essa ferramenta utiliza o protocolo SNMP e agentes próprios para monitorar e gerenciar os recursos, garantindo assim 
uma gerência por parte da provedora e pelos clientes em monitorar o status de ANS dos serviços ofertados na nuvem privada.

Para gerenciar a parte de armazenamento na nuvem foi utilizada a ferramenta FreeNAS, que é desenvolvida na plataforma do sistema operacional FreeBSD e utilizada para administrar e gerenciar storages.

$\mathrm{Na}$ automatização do processo de gerência de configuração do ambiente de nuvem foi utilizada a ferramenta puppet, que automatiza o processo de configuração das VMs, e foi através dela que se pode trabalhar provisionamento, automatização, gerência de mudanças, manipulação de configurações, além disto, e consequentemente foi possível iniciar também um processo de documentação dos ambientes envolvidos, além do planejamento de mudanças.

\subsection{Descrição do cenário implantado}

A atividade inicial no processo de implementação foi o da apresentação de justificativa técnica e organizacional para a alta gestão da provedora, apresentando que benefício à nuvem privada traria para a provedora e seus clientes, comparado com a infraestrutura antes existente e problemática. Em seguida, iniciou-se o processo de levantamento de dados das necessidades de infraestrutura e softwares que atenderia à demanda dos clientes, após essa fase projetou-se o ambiente tecnológico necessário para criar a nuvem.

As etapas realizadas para a implantação da nuvem privada da provedora são contempladas com diversas atividades, estas estão descritas no fluxograma a seguir na figura 3 : 
Figura 3 - Fluxograma com as etapas para a implantação da nuvem

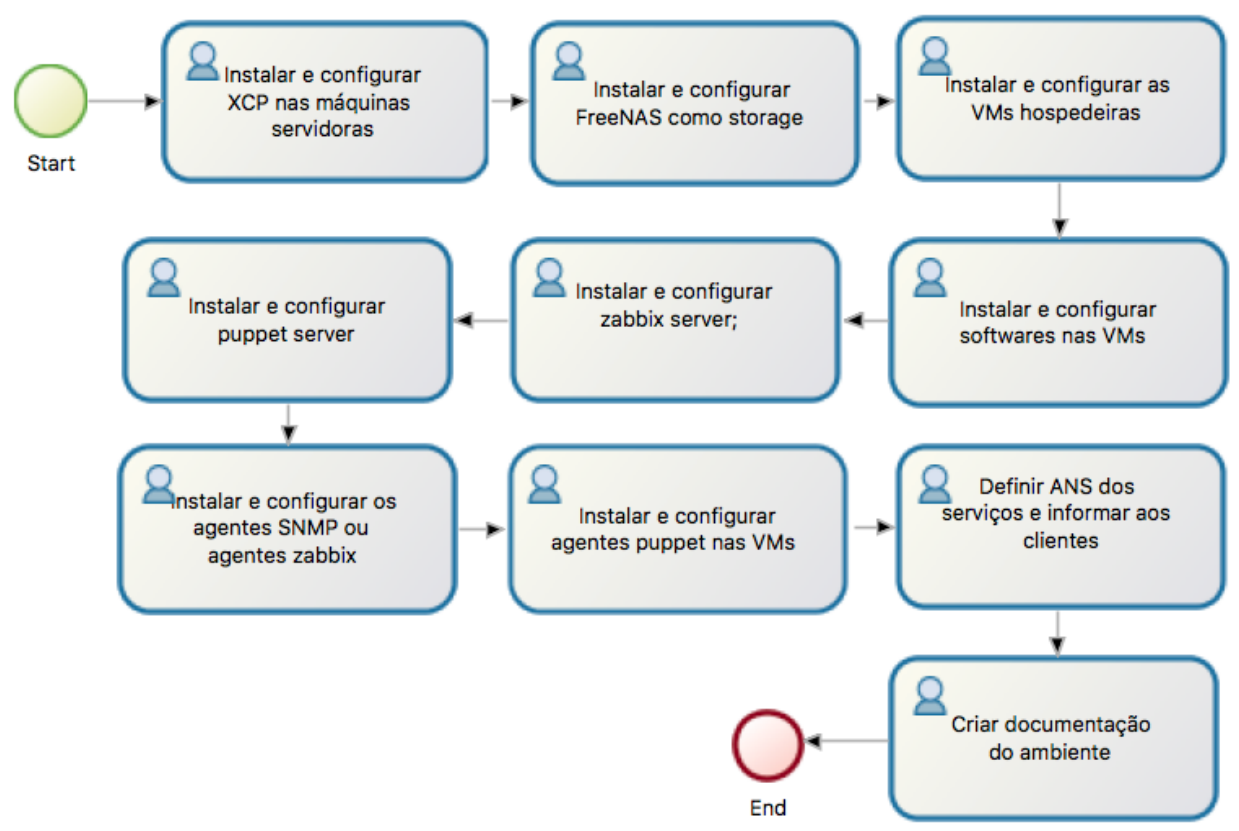

\subsection{Resultados obtidos com a implantação do cenário de nuvem privada para provedora}

A implantação de nuvem privada da provedora agregou diversas vantagens, tanto para a equipe técnica que administra o ambiente como para os clientes que utilizam os serviços da nuvem. Foram definidos 8 valores que a infraestrutura de nuvem trouxe para a provedora. O primeiro foi a Diminuição de tempo em atendimentos: Com a nova estrutura de nuvem, a disponibilização de um ambiente laaS ou SaaS é rápido e simples. O que antes demoraria 2 dias para ser criado, com a nuvem leva-se em torno de 20 minutos dependendo da necessidade. O segundo, uma Melhor administração do ambiente por parte da equipe técnica da provedora: No novo ambiente de nuvem, a administração do ambiente se tornou mais simples, já que todo ambiente está integrado e centralizado. A terceira, Padronização da infraestrutura: Com a implantação da nuvem privada, todos os dados estão centralizados dentro de um padrão. A quarta, o Atendimento às 
demandas dos clientes da provedora: A nova estrutura da provedora consegue atender às necessidades e demandas dos clientes, pois possui infraestrutura para ofertar os serviços, e como há a racionalização de recursos com a técnica de virtualização, ficou mais fácil gerenciar os recursos. A quinta, uma Melhor gerenciamento de recursos do ambiente: Com a nuvem, os recursos computacionais agora são gerenciados e remanejados conforme a demanda e necessidade da provedora e seus clientes. Como sexto valor, a Redução de consumo de energia com servidores: Na utilização da virtualização houve uma redução no número de máquinas físicas, assim ocasionando uma redução no consumo de energia do parque computacional. As informações de consumo da proposta são: Potência da fonte - 850 Watt; Número de fontes - 16 quantidades; e Tempo de funcionamento em horas - 24 horas. O sétimo, a Redução de custos com equipamentos: Antes da implantação do cenário de computação em nuvem com a virtualização, existia um ambiente com mais de 20 máquinas físicas e nem todas com redundância de dados. Com a proposta, o cenário virtualizou praticamente $80 \%$ das máquinas físicas, e encontra-se com 4 máquinas específicas, assim virtualizando mais de 30 máquinas virtuais.

O custo somado de aquisição das 20 máquinas utilizadas na infraestrutura da provedora era em torno de $\mathrm{R} \$ 320.000,00$. Para a aquisição da proposta investia-se $\mathrm{R} \$ 190.000,00$ (cento e noventa mil reais), ou seja, o valor do investimento da proposta corresponde a $60,8 \%$ do custo anteriormente utilizado na estrutura legada. Outro fator que se constitui na redução de custos foi com contrato de garantia de manutenção, antes se pagava um custo anual de $R \$ 65.000,00$, atualmente esse custo diminui para $R \$ 16.000,00$. Se precisasse de mais máquina, o valor seria aumentado consequentemente. Assim, se pode mensurar valores para a adoção da provedora do provedor UnderCloud para hospedar a estrutura de suas 10 máquinas físicas, em um ano teria o investimento $R \$ 36.000,00$, caso se utilizasse o provedor Amazon o investimento seria $\mathrm{R} \$ 51.840,00$. Pode-se, por exemplo, mensurar o valor para 30 máquinas (quantitativo este de máquinas instanciadas na proposta deste trabalho), o valor subiria para um investimento anual no provedor UnderCloud para 
$R \$ 108.000,00$ e no Amazon para $R \$ 155.520,00$. Por fim, o oitavo valor que a infraestrutura de nuvem trouxe para a provedora foi a Otimização de recursos computacionais: Na nova infraestrutura de nuvem, o ambiente virtualizado usa apenas $60 \%$ de sua capacidade total de recursos computacionais, em seus horários de maior consumo, tornando possível atender futuras demandas.

\subsection{Resolução dos problemas da provedora, conformidades com segurança da informação e computação em nuvem e tratamento dos riscos mapeados no ambiente convencional da provedora}

O cenário implantado de nuvem privada da provedora, além de garantir alguns benefícios já citados neste trabalho, está em conformidade com as melhores práticas de mercado. Os quadros 6, 7 e 8 ilustram os processos das documentações regulatórias, como, características essenciais das melhores práticas do NIST (2011), melhores práticas da CSA (2011) e ISO_2 (2005).

Como apresentado no quadro 4, que ilustrou o processo de análise e avaliação de risco referente ao cenário antes da implantação da proposta de nuvem para a provedora, esses dados tabulados nortearam a realização da fase de tratamento de risco, a qual é ilustrada no quadro 9.

Após a implantação do cenário proposto neste estudo, foram solucionados ou minimizados todos os problemas com o modelo de oferta de serviços de $\mathrm{TI}$ da provedora já descritos neste trabalho. O quadro 5 apresenta a solução adotada e implantada para solução de cada problema.

Quadro 5 - Solução adotada para solucionar problemas da provedora

\begin{tabular}{|c|l|l|}
\hline ID & \multicolumn{1}{|c|}{ Ativo } & \multicolumn{1}{c|}{ Ameaça } \\
\hline 1 & Não otimização de recursos & $\begin{array}{l}\text { - A adoção da virtualização com a ferramenta } \\
\text { XCP, possibilitou um melhor dimensionamento } \\
\text { de recursos computacionais na infraestrutura. }\end{array}$ \\
\hline 2 & $\begin{array}{l}\text { Problemas com versões de } \\
\text { aplicações de teste e } \\
\text { produção } \\
\text { virtualização utilizando-se a XCP, garantem-se } \\
\text { ambientes de desenvolvimento, teste e } \\
\text { produção com a mesma configuração. } \\
\text { - Com a adoção da ferramenta puppet, agora é } \\
\text { possível de uma forma muito automatizada } \\
\text { realizar configurações em várias máquinas ao }\end{array}$ \\
\hline
\end{tabular}




\begin{tabular}{|c|c|c|}
\hline & & $\begin{array}{l}\text { mesmo tempo, garantindo a integridade dos } \\
\text { dados. }\end{array}$ \\
\hline 3 & $\begin{array}{l}\text { Não atendimento de } \\
\text { necessidades de requisições } \\
\text { de softwares demandados } \\
\text { das secretarias }\end{array}$ & $\begin{array}{l}\text { - Com o ambiente otimizado e utilizando o } \\
\text { ambiente de nuvem, pode-se disponibilizar } \\
\text { Infraestrutura ou Software como serviço } \\
\text { conforme a necessidade das secretarias. }\end{array}$ \\
\hline 4 & $\begin{array}{l}\text { Demora no processo de } \\
\text { de ambiente }\end{array}$ & $\begin{array}{l}\text { - Com o ambiente de nuvem implantada } \\
\text { utilizando como base a virtualização, o } \\
\text { processo de criação de uma VM é rápido e } \\
\text { simples. }\end{array}$ \\
\hline 5 & $\begin{array}{l}\text { Gerenciamento não } \\
\text { centralizado dos servidores }\end{array}$ & $\begin{array}{l}\text { - Com o ambiente todo em nuvem virtualizado, } \\
\text { hoje se pode gerenciar de forma mais eficaz, } \\
\text { uma vez que todas as VMs estão } \\
\text { centralizadas em uma máquina física. }\end{array}$ \\
\hline 6 & $\begin{array}{l}\text { Probabilidade de risco maior } \\
\text { em caso de incidentes de } \\
\text { segurança física }\end{array}$ & $\begin{array}{l}\text { - Com a adoção de redundância de servidores } \\
\text { física e logicamente, em caso de paralisação } \\
\text { de um servidor físico a outra máquina backup } \\
\text { assume todos os serviços. }\end{array}$ \\
\hline 7 & $\begin{array}{l}\text { Dificuldade de garantir a } \\
\text { disponibilidade com } \\
\text { redundância dos servidores }\end{array}$ & $\begin{array}{l}\text { - Com a adoção de nuvem e centralização dos } \\
\text { serviços em VMs, agora é muito mais simples } \\
\text { garantir a redundância dos servidores, já que o } \\
\text { número de máquinas físicas é bem menor que } \\
\text { antes. }\end{array}$ \\
\hline 8 & $\begin{array}{l}\text { Gerenciamento do ambiente } \\
\text { mais complexo }\end{array}$ & $\begin{array}{l}\text { - Com o ambiente centralizado, torna-se menos } \\
\text { oneroso o processo de administração do } \\
\text { ambiente, outro fator que agregou para a } \\
\text { administração do novo ambiente (nuvem), foi a } \\
\text { implantação da ferramenta zabbix para } \\
\text { gerenciar todos os recursos computacionais }\end{array}$ \\
\hline 9 & $\begin{array}{l}\text { Maior dificuldade para } \\
\text { escalabilidade de recursos } \\
\text { computacionais }\end{array}$ & $\begin{array}{l}\text { - Com a otimização dos recursos } \\
\text { computacionais, agora se pode projetar e } \\
\text { planejar o crescimento do ambiente de forma } \\
\text { mais precisa. }\end{array}$ \\
\hline 10 & $\begin{array}{l}\text { Maior dificuldade em deixar o } \\
\text { ambiente computacional em } \\
\text { conformidade com normas } \\
\text { de segurança }\end{array}$ & $\begin{array}{l}\text { - Para o processo de implantação de nuvem } \\
\text { privada para a provedora foram usadas como } \\
\text { referência, melhores práticas e normas que } \\
\text { regem a segurança da informação, como, } \\
\text { NIST, CSA, ISO } 27002 \text {. Conformidades essas } \\
\text { no ambiente legado não utilizadas. }\end{array}$ \\
\hline
\end{tabular}

Fonte: 0 autor. 
Quadro 6 - Características essenciais do NIST implantadas em nuvem da PRODAP

\begin{tabular}{|c|c|c|c|}
\hline ID & $\begin{array}{l}\text { Características } \\
\text { essenciais }\end{array}$ & $\begin{array}{c}\text { Evidência implantada na } \\
\text { organização }\end{array}$ & $\begin{array}{l}\text { Evidência na organização } \\
\text { antes da implantação }\end{array}$ \\
\hline 1 & $\begin{array}{l}\text { Amplo Acesso à } \\
\text { Rede }\end{array}$ & $\begin{array}{l}\text { - Os serviços são } \\
\text { disponibilizados através da } \\
\text { Intranet e pela Internet da } \\
\text { PRODAP. }\end{array}$ & SIM \\
\hline 2 & $\begin{array}{l}\text { Rápida } \\
\text { Elasticidade }\end{array}$ & $\begin{array}{l}\text { - Uma vez feito o pedido } \\
\text { formalizado de aumento de } \\
\text { recursos computacionais na } \\
\text { nuvem, rapidamente é liberado } \\
\text { e não são definidos limites de } \\
\text { recursos. }\end{array}$ & NÃO \\
\hline 3 & $\begin{array}{l}\text { Serviços } \\
\text { Mensuráveis }\end{array}$ & $\begin{array}{l}\text { - Com a adoção da ferramenta } \\
\text { de gerenciamento de recursos } \\
\text { zabbix, as secretarias } \\
\text { conseguem monitorar o } \\
\text { consumo de seus recursos } \\
\text { disponibilizados na nuvem. }\end{array}$ & NÃO \\
\hline 4 & $\begin{array}{l}\text { Auto-Serviço sob } \\
\text { demanda }\end{array}$ & $\begin{array}{l}\text { - Caso haja demanda de mais } \\
\text { recursos, basta o cliente } \\
\text { formalizar o pedido para que } \\
\text { seja atendido. }\end{array}$ & NÃO \\
\hline 5 & $\begin{array}{l}\text { Pool de } \\
\text { Recursos }\end{array}$ & $\begin{array}{l}\text { - Com a implantação do } \\
\text { cenário de nuvem privada, as } \\
\text { necessidades dos clientes são } \\
\text { atendidas conforme a } \\
\text { demanda deles. }\end{array}$ & NÃO \\
\hline
\end{tabular}

Fonte: 0 autor.

Quadro 7 - Atividade do CSA v3.0 implantadas na nuvem da provedora

\begin{tabular}{|c|c|c|c|}
\hline $\begin{array}{c}\text { Seção } \\
\text { CSA } \\
\text { v3.0 }\end{array}$ & $\begin{array}{c}\text { Atividade do } \\
\text { CSA v3.0 }\end{array}$ & \multicolumn{1}{|c|}{$\begin{array}{c}\text { Evidência implantada na } \\
\text { organização }\end{array}$} & $\begin{array}{c}\text { Evidência na } \\
\text { organização antes } \\
\text { da implantação }\end{array}$ \\
\hline Seção I I & $\begin{array}{l}\text { Arquitetura de } \\
\text { Nuvem. }\end{array}$ & $\begin{array}{l}\text { - Implantação do cenário } \\
\text { centralizado utilizando a } \\
\text { virtualização e hospedando } \\
\text { SaaS na nuvem privada }\end{array}$ & NÃO \\
\hline
\end{tabular}




\begin{tabular}{|c|c|c|c|}
\hline \multirow{3}{*}{ Seção II } & $\begin{array}{l}\text { Gerenciamento } \\
\text { de Auditoria e } \\
\text { Conformidade. }\end{array}$ & $\begin{array}{l}\text { - Com a implantação da nuvem } \\
\text { privada e hospedagem dos } \\
\text { serviços, foram criados o ANS e } \\
\text { responsabilidades entre as } \\
\text { partes } \\
\text { - Em caso de descoberta por } \\
\text { parte do provedor em algum } \\
\text { serviço hospedado, esteja fora } \\
\text { das políticas definidas, o } \\
\text { provedor poderá auditar as } \\
\text { contas de email como exemplo. }\end{array}$ & NÃO \\
\hline & $\begin{array}{l}\text { Segurança dos } \\
\text { Dados e } \\
\text { Gerenciamento } \\
\text { da Informação }\end{array}$ & $\begin{array}{l}\text { - Com a centralização dos dados } \\
\text { na nuvem privada da provedora, } \\
\text { todos os acessos são } \\
\text { monitorados por elementos de } \\
\text { segurança de redes de } \\
\text { computadores, como: Firewall, } \\
\text { proxy. }\end{array}$ & PARCIAL \\
\hline & $\begin{array}{l}\text { Interoperabilidad } \\
\text { e e Portabilidade }\end{array}$ & $\begin{array}{l}\text { - Com a centralização dos dados } \\
\text { na nuvem, permitiu-se a } \\
\text { integração de vários ambientes, } \\
\text { atualmente podem-se integrar } \\
\text { diversos sistemas em diversas } \\
\text { plataformas. }\end{array}$ & PARCIAL \\
\hline \multirow{3}{*}{ Seção III } & $\begin{array}{l}\text { Segurança } \\
\text { Tradicional, } \\
\text { Continuidade de } \\
\text { Negócios e } \\
\text { Recuperação de } \\
\text { Desastres. }\end{array}$ & $\begin{array}{l}\text { - Com a centralização dos dados } \\
\text { na nuvem, permitiu-se de forma } \\
\text { mais simples implantar } \\
\text { mecanismos de segurança, } \\
\text { ainda foi possível garantir a } \\
\text { contingência dos dados com a } \\
\text { redundância do ambiente. Esse } \\
\text { ambiente contingenciado poderia } \\
\text { ser reaplicado para ambiente } \\
\text { hospedado em outra localização } \\
\text { física. }\end{array}$ & NÃO \\
\hline & $\begin{array}{l}\text { Respostas a } \\
\text { Incidentes. }\end{array}$ & $\begin{array}{l}\text { - Com a implantação do software } \\
\text { zabbix foi possível gerenciar } \\
\text { qualquer evento que esteja em } \\
\text { operação nas VMs, nesse } \\
\text { sentido a equipe técnica da } \\
\text { PRODAP pode identificar de } \\
\text { forma mais assertiva um } \\
\text { incidente antes de ocorrer um } \\
\text { problema. }\end{array}$ & PARCIAL \\
\hline & Virtualização. & - Toda a criação da & NÃO \\
\hline
\end{tabular}




\begin{tabular}{|l|l|l|}
\hline & $\begin{array}{l}\text { infraestrutura da nuvem privada } \\
\text { da PRODAP foi realizada com a } \\
\text { técnica de virtualização dos } \\
\text { servidores que } \\
\text { consequentemente hospedaram } \\
\text { os softwares com um serviço. }\end{array}$ & \\
\hline
\end{tabular}

Fonte: o autor.

Quadro 8 - Atividades da ISSO/IEC 27002 implantadas na nuvem da provedora

\begin{tabular}{|c|c|c|c|}
\hline $\begin{array}{l}\text { Seção da } \\
\text { ISO/IEC } 27002\end{array}$ & $\begin{array}{l}\text { Categoria da } \\
\text { ISO/IEC } 27002\end{array}$ & $\begin{array}{c}\text { Evidência implantada na } \\
\text { organização }\end{array}$ & $\begin{array}{l}\text { Evidência na } \\
\text { organização } \\
\text { antes da } \\
\text { implantação }\end{array}$ \\
\hline $\begin{array}{l}\text { Seção III - } \\
\text { Gestão de } \\
\text { Ativos }\end{array}$ & $\begin{array}{l}3.1 \\
\text { Responsabilidades } \\
\text { pelos ativos }\end{array}$ & $\begin{array}{l}\text { - Na solicitação dos serviços } \\
\text { são informadas as } \\
\text { responsabilidades das partes } \\
\text { (provedor e clientes). } \\
\text { - Com o novo ambiente de } \\
\text { nuvem e as ferramentas } \\
\text { implantadas permitiu-se } \\
\text { realizar inventário dos ativos } \\
\text { hospedados. }\end{array}$ & NÃO \\
\hline \multirow{5}{*}{$\begin{array}{l}\text { Seção VI - } \\
\text { Gerenciamento } \\
\text { das Operações } \\
\text { e } \\
\text { Comunicações }\end{array}$} & $\begin{array}{l}6.1 \text { Procedimentos } \\
\text { e } \\
\text { responsabilidades } \\
\text { operacionais }\end{array}$ & $\begin{array}{l}\text { - Com o novo ambiente criado } \\
\text { desde a fase inicial foram } \\
\text { criados procedimentos } \\
\text { operacionais para } \\
\text { entendimento e definição de } \\
\text { responsabilidades para a } \\
\text { equipe. }\end{array}$ & NÃO \\
\hline & $\begin{array}{l}\text { 6.3 Planejamento e } \\
\text { aceitação dos } \\
\text { sistemas }\end{array}$ & $\begin{array}{l}\text { - Planejar a capacidade de } \\
\text { sistemas antes da } \\
\text { hospedagem.- Definir critérios } \\
\text { para atualização de softwares } \\
\text { hospedados. }\end{array}$ & PARCIAL \\
\hline & $\begin{array}{l}\text { 6.5 Cópias de } \\
\text { segurança }\end{array}$ & $\begin{array}{l}\text { - Com a virtualização na } \\
\text { nuvem, a realização de cópias } \\
\text { de segurança das VMs se } \\
\text { tornou algo mais flexível. }\end{array}$ & NÃO \\
\hline & $\begin{array}{l}6.6 \\
\text { Gerenciamentos } \\
\text { da segurança em } \\
\text { redes }\end{array}$ & $\begin{array}{l}\text { - Gerenciar a rede com } \\
\text { elementos de segurança } \\
\text { como: Firewall, IDS, proxy e } \\
\text { outros. }\end{array}$ & SIM \\
\hline & $\begin{array}{l}6.9 \text { Comércio } \\
\text { eletrônico }\end{array}$ & $\begin{array}{l}\text { - Definir uma ferramenta } \\
\text { padrão de uso e gerência de }\end{array}$ & PARCIAL \\
\hline
\end{tabular}


Utilização de nuvem privada em ambiente corporativo como estratégia para sustentabilidade nas empresas públicas

\begin{tabular}{|c|c|c|c|}
\hline & & $\begin{array}{l}\text { email dentro da estrutura } \\
\text { governamental hospedada na } \\
\text { nuvem. }\end{array}$ & \\
\hline & $\begin{array}{l}6.10 \\
\text { Monitoramento }\end{array}$ & $\begin{array}{l}\text { - Monitorar os acessos dos } \\
\text { usuários. } \\
\text { - Registrar logs de eventos, } \\
\text { seja de acessos, de falhas, de } \\
\text { desempenho. }\end{array}$ & PARCIAL \\
\hline \multirow{3}{*}{$\begin{array}{l}\text { Seção VII - } \\
\text { Controle de } \\
\text { acesso }\end{array}$} & $\begin{array}{l}\text { 7.2 Registro de } \\
\text { usuário }\end{array}$ & $\begin{array}{l}\text { - Registrar por meio de } \\
\text { autenticação o acesso dos } \\
\text { usuários. }\end{array}$ & PARCIAL \\
\hline & $\begin{array}{l}7.3 \\
\text { Responsabilidades } \\
\text { dos usuários }\end{array}$ & $\begin{array}{l}\text { - Cada usuário que se utiliza } \\
\text { dos serviços hospedados na } \\
\text { nuvem, tem } \\
\text { responsabilidades. }\end{array}$ & NÃO \\
\hline & $\begin{array}{l}7.4 \text { Controles de } \\
\text { acesso à rede }\end{array}$ & $\begin{array}{l}\text { - O acesso à rede dos } \\
\text { serviços hospedados na } \\
\text { nuvem é controlado por meio } \\
\text { de autenticação. }\end{array}$ & PARCIAL \\
\hline \multirow{2}{*}{$\begin{array}{l}\text { Seção VIII - } \\
\text { Aquisição, } \\
\text { desenvolviment } \\
\text { o e } \\
\text { manutenção de } \\
\text { sistemas de } \\
\text { informação. }\end{array}$} & $\begin{array}{l}8.5 \text { Segurança em } \\
\text { processo de } \\
\text { desenvolvimento e } \\
\text { de suporte }\end{array}$ & $\begin{array}{l}\text { - O ambiente de nuvem prover } \\
\text { diversos ambientes e eles são } \\
\text { segregados, ambiente como: } \\
\text { desenvolvimento, } \\
\text { teste/homologação e } \\
\text { produção. }\end{array}$ & NÃO \\
\hline & $\begin{array}{l}\text { 8.6 Gestão de } \\
\text { vulnerabilidades } \\
\text { técnicas }\end{array}$ & $\begin{array}{l}\text { - Nos serviços hospedados na } \\
\text { nuvem são realizados testes } \\
\text { de vulnerabilidades de redes } \\
\text { e aplicações com a finalidade } \\
\text { de detecção e correção } \\
\text { posteriormente. }\end{array}$ & NÃO \\
\hline $\begin{array}{l}\text { Seção IX - } \\
\text { Gestão de } \\
\text { incidentes de } \\
\text { segurança da } \\
\text { informação }\end{array}$ & $\begin{array}{l}\text { 9.1 Notificação de } \\
\text { fragilidade e } \\
\text { eventos de } \\
\text { segurança da } \\
\text { informação }\end{array}$ & $\begin{array}{l}\text { - No ambiente, se houver a } \\
\text { detecção de fragilidades de } \\
\text { segurança, os clientes são } \\
\text { informados por email ou por } \\
\text { telefone sobre o cenário. }\end{array}$ & NÃO \\
\hline $\begin{array}{l}\text { Seção X - } \\
\text { Gestão de } \\
\text { continuidade de } \\
\text { negócio }\end{array}$ & $\begin{array}{l}10.1 \text { Aspectos da } \\
\text { gestão de } \\
\text { continuidade do } \\
\text { negócio, relativos à } \\
\text { segurança da } \\
\text { informação. }\end{array}$ & $\begin{array}{l}\text { - Com o novo cenário } \\
\text { implantado de nuvem privada, } \\
\text { foi possível pensar-se em } \\
\text { projeto de plano de } \\
\text { continuidade de negócio, mas } \\
\text { no momento encontra-se } \\
\text { implantado apenas o plano de } \\
\text { contingência de dados que é } \\
\text { uma atividade do plano de }\end{array}$ & NÃO \\
\hline
\end{tabular}




\begin{tabular}{|c|c|c|c|}
\hline & & negócio. & \\
\hline $\begin{array}{l}\text { Seção XI - } \\
\text { Conformidade }\end{array}$ & $\begin{array}{l}11.2 \text { Conformidade } \\
\text { com normas e } \\
\text { políticas de } \\
\text { segurança da } \\
\text { informação e } \\
\text { conformidade } \\
\text { técnica }\end{array}$ & $\begin{array}{l}\text { - O novo ambiente está em } \\
\text { conformidade com políticas } \\
\text { internas da PRODAP e com } \\
\text { melhores práticas de } \\
\text { segurança e computação em } \\
\text { nuvem. }\end{array}$ & NÃO \\
\hline
\end{tabular}

Fonte: o autor. 
Quadro 9 - Tratamento do risco na provedora

\begin{tabular}{|c|c|c|c|c|}
\hline ID & Ativo & $\begin{array}{c}\text { Risco } \\
\text { antes do } \\
\text { tratamento } \\
\text { de risco }\end{array}$ & $\begin{array}{l}\text { Solução de tratamento de } \\
\text { risco }\end{array}$ & $\begin{array}{c}\text { Risco } \\
\text { após o } \\
\text { tratamento } \\
\text { de risco }\end{array}$ \\
\hline 1 & $\begin{array}{l}\text { otimização de } \\
\text { recursos } \\
\text { computacionais }\end{array}$ & médio (8) & $\begin{array}{l}\text { - adoção de técnica de } \\
\text { virtualização utilizando a } \\
\text { ferramenta xcp para criar a } \\
\text { infraestrutura de nuvem privada } \\
\text { para otimização de recursos } \\
\text { computacionais ofertados para } \\
\text { as secretarias. }\end{array}$ & $\begin{array}{c}\text { baixo } \\
\text { (4) }\end{array}$ \\
\hline 2 & $\begin{array}{l}\text { garantia de } \\
\text { versionamento } \\
\text { de ambientes }\end{array}$ & médio (12) & $\begin{array}{l}\text { - criação de ambiente de teste e } \\
\text { desenvolvimento em ambiente } \\
\text { virtualizado no xcp igual ao } \\
\text { ambiente de produção. } \\
\text { - utilização da ferramenta puppet } \\
\text { server para gerenciar as } \\
\text { configurações das máquinas } \\
\text { virtuais. }\end{array}$ & $\begin{array}{c}\text { baixo } \\
(6)\end{array}$ \\
\hline 3 & $\begin{array}{l}\text { atendimento às } \\
\text { necessidades } \\
\text { das secretarias }\end{array}$ & baixo (4) & $\begin{array}{l}\text { - utilização da virtualização na } \\
\text { nuvem privada para otimizar } \\
\text { recursos computacionais e } \\
\text { atender as demandas das } \\
\text { secretarias. }\end{array}$ & $\begin{array}{c}\text { baixo } \\
\text { (2) }\end{array}$ \\
\hline 4 & $\begin{array}{l}\text { demora no } \\
\text { processo de } \\
\text { implementação } \\
\text { de ambiente de } \\
\text { produção }\end{array}$ & médio (8) & $\begin{array}{l}\text { - utilização da virtualização na } \\
\text { nuvem privada para otimizar } \\
\text { recursos computacionais e } \\
\text { atender às demandas das } \\
\text { secretarias. }\end{array}$ & $\begin{array}{l}\text { baixo } \\
(2)\end{array}$ \\
\hline 5 & $\begin{array}{l}\text { Gerenciamento } \\
\text { descentralizado }\end{array}$ & médio (12) & $\begin{array}{l}\text { - utilização da nuvem privada } \\
\text { para centralizar todos os } \\
\text { serviços nas vms apenas nas } \\
\text { máquinas físicas que foram } \\
\text { utilizadas na proposta. }\end{array}$ & $\begin{array}{l}\text { baixo } \\
(6)\end{array}$ \\
\hline 6 & segurança física & baixo (6) & $\begin{array}{l}\text { - adoção de duas máquinas } \\
\text { físicas para a solução de nuvem } \\
\text { para oferta de serviços, sendo } \\
\text { uma de produção e a outra de } \\
\text { backup, em caso de queda ou } \\
\text { queima da máquina principal a } \\
\text { máquina backup assume o } \\
\text { controle. }\end{array}$ & $\begin{array}{l}\text { baixo } \\
\text { (3) }\end{array}$ \\
\hline
\end{tabular}




\begin{tabular}{|c|c|c|c|c|}
\hline 7 & $\begin{array}{l}\text { garantir a } \\
\text { disponibilidade }\end{array}$ & baixo (6) & $\begin{array}{l}\text { - utilização de solução de } \\
\text { redundância e replicação de } \\
\text { dados da máquina de produção } \\
\text { para a máquina backup, essa } \\
\text { replicação é configurada de } \\
\text { forma automatizada nas } \\
\text { ferramentas xcp e freenas, onde } \\
\text { a replicação é feita duas vezes } \\
\text { no dia. sendo uma no intervalo } \\
\text { do almoço (12h às } 14 \mathrm{~h} \text { ) e a outra } \\
\text { às } 19 \mathrm{~h} \text {. }\end{array}$ & $\begin{array}{l}\text { baixo } \\
\text { (3) }\end{array}$ \\
\hline 8 & $\begin{array}{l}\text { Gerenciamento } \\
\text { complexo }\end{array}$ & médio (8) & $\begin{array}{l}\text { - centralização dos dados na } \\
\text { nuvem com a ferramenta xcp e a } \\
\text { adoção da ferramenta puppet } \\
\text { server para garantir a } \\
\text { integridade das configurações } \\
\text { em todas as vms. }\end{array}$ & $\begin{array}{l}\text { baixo } \\
\text { (3) }\end{array}$ \\
\hline 9 & $\begin{array}{l}\text { dificuldade para } \\
\text { escalabilidade }\end{array}$ & baixo (2) & $\begin{array}{l}\text { - utilização da virtualização na } \\
\text { nuvem privada para otimizar } \\
\text { recursos computacionais e } \\
\text { atender as demandas das } \\
\text { secretarias. }\end{array}$ & $\begin{array}{l}\text { baixo } \\
\text { (1) }\end{array}$ \\
\hline 10 & $\begin{array}{l}\text { dificuldade em } \\
\text { realizar } \\
\text { conformidade } \\
\text { com segurança } \\
\text { da informação }\end{array}$ & médio (8) & $\begin{array}{l}\text { - a implantação do cenário de } \\
\text { nuvem privada da prodap foi } \\
\text { planejada a utilizar em } \\
\text { conformidade com melhores } \\
\text { práticas e normas de segurança } \\
\text { da informação como nist, csa e } \\
\text { iso } 27002 \text {. }\end{array}$ & $\begin{array}{l}\text { baixo } \\
\text { (2) }\end{array}$ \\
\hline
\end{tabular}

Fonte: o autor.

\section{CONSIDERAÇÕES FINAIS}

Visando atender aos objetivos específicos detalhados deste estudo, este trabalho buscou expandir os horizontes da pesquisa sobre a sustentabilidade da computação em nuvem, e mostrar ainda que impactos positivos à implantação de uma nuvem privada podem trazer para uma empresa governamental estadual em um modelo de provedor de serviços aderente às conformidades de segurança da informação, oportunizando mitigar preocupações de segurança computacional, com o uso racional dos recursos tecnológicos. Neste sentido, o estudo apresentou aspectos qualitativos e quantitativos os quais ilustram que benefícios uma 
organização de processamento de dados pública pode ter com a utilização de nuvem privada, benefícios esses como redução de custos, melhora de gerenciamento dos dados, padronização da infraestrutura computacional, documentação de processos e procedimentos utilizados, e melhor adequação dos recursos necessários para um uso conscientes dos recursos disponíveis, buscando diminuir o consumo desnecessário,.

A proposta abordou apenas a utilização de serviços na nuvem privada, não abordando nuvem pública ou híbrida. Isso ocorre por algumas regulamentações que tratam requisitos de segurança no armazenamento de dados, que deve ser realizado internamente pela organização. Sobretudo, já existem empresas públicas utilizando soluções híbridas e inclusive as soluções ferramentais de computação em nuvem já contemplam o tratamento de dados privado e público.

Este trabalho apresentou também os benefícios obtidos com a implantação da solução em nuvem privada para a provedora, comparado ao modelo anteriormente utilizado para oferta de serviços pela empresa pública. Além de todo cenário estar aderente às documentações de melhores práticas de segurança da informação e segurança em computação em nuvem como (NIST, 2011), (ISO_2, 2005) e (CSA, 2011). Possibilitando ainda a implementação realizar a mitigação de riscos no que tange à segurança da informação no processo de tratamento do risco, reduzindo assim a possibilidade de incidentes de segurança ocorrem no ambiente de oferta de serviços da provedora.

Para validar a proposta deste trabalho referente à mitigação de risco, foi adotada a metodologia avaliativa de análise e avaliação de riscos. Após a análise foi realizado o tratamento do risco e avaliado o quanto foi mitigado de risco com a adoção da proposta. O trabalho contribuiu para que empresas no segmento público possam melhorar a oferta de seus serviços utilizando um cenário de nuvem privada em sua própria infraestrutura, e garantindo a segurança dos dados nesse cenário. $\mathrm{O}$ trabalho ainda contribui academicamente apresentando passos utilizados para uma proposta de implementação sustentável em nuvem privada utilizando ferramentas em software livre e avaliando o risco. Outro fator agregador é que a proposta deste 
trabalho contemplou a visão de garantir a segurança da informação na nuvem conforme é fomentado atualmente em instruções normativas pelo Governo Federal do Brasil.

Apresentou também que o custo da energia elétrica para data centers é um custo de operação que deve ser levado em consideração e pode ser controlado, reduzindo assim o desperdício. Um bom projeto de um datacenter que prevê baixo custo de energia traz economias para outras áreas, como o capital e custos operacionais associados à refrigeração, alimentação e então a redução de espaço físico. Comprovando que as probabilidades de economia são reais e o investimento necessário é pequeno frente aos grandes benefícios.

Oportunidades futuras de pesquisa incluem o desenvolvimento de um framework para que os clientes possam ter a autonomia de criar e personalizar a sua infraestrutura ou escolha de softwares dentro da nuvem privada da provedora.

\section{REFERÊNCIAS}

ANDRADE, Hilson G. V. (2013). Estudo de viabilidade de um serviço de Cloud Storage, utilizando recursos ociosos, por uma Operadora de Telecomunicações. Dissertação. CIN/UFPE.

ARMBRUST, et al. (2009). Above the Clouds: A Berkeley View of Cloud Computing. EECS Department, University of California, Berkeley.

CSA, Cloud Security Alliance v3. (2011). Security Guidance for Critical Areas of Focus in Cloud Computing.

DATAPREV. (2013). Computação em Nuvem no Governo Federal. Em: $<$ http://portal.dataprev.gov.br>.

DSIC. (2013). Diretrizes para a utilização de tecnologias de computação em nuvem. Em: <http://dsic.planalto.gov.br/legislacaodsic/51>. 
Utilização de nuvem privada em ambiente corporativo como estratégia para

sustentabilidade nas empresas públicas

GHINATO, P. Publicado como $2^{\circ}$. cap. do Livro Produção \& Competitividade:

Aplicações e Inovações, Ed.: Adiel T. de Almeida \& Fernando M. C. Souza, Edit. da UFPE, Recife, 2000.

HARRIS, J. G.; ALTER, A. E. (2010). Cloudrise: Rewards and Risks at the Dawn of Cloud Computing. Accenture. Research Report.

INFO. (2013). Governo brasileiro ganha sistema de computação em nuvem. Disponível em: <http://info.abril.com.br>.

ISO_2, International Organization for Standardization. (2005). Code of practice for information security management.

MARINS, C. E. (2009). Desafios da informática forense no cenário de Cloud Computing. Proceedings of the Fourth International Conference of Computer Science. p. 78-85. ISSN 1980-1114. ABEAT (Ed.). Natal, RN, Brazil.

MARCUSE, Herbert. A Ideologia da Sociedade Industrial. 5ed. Rio de Janeiro: Zahar, 1979.

MARSTON, S. et al. (2011). Cloud Computing - The business perspective. Decision Support Systems, V. 51, p. 176-189.

MATHEWS, Jeanna N. et al. Executando o Xen. Rio de Janeiro: Alta Books, 2009.

NEDER, Ricardo Toledo. Crise socioambiental: estado \& sociedade civil no Brasil, 1982-1998. Editora: Anablume. 2002. Disponível em:

$<$ http://books.google.com.br/books?id=vzq89-

3bFSMC\&dq=victor+lebow\&source=gbs_navlinks_s $>$. Acessado em 10/07/2011

NIST. (2011). SP 800-145 - The NIST Definition of Cloud Computing.

NIST_800-144. (2011). SP 800-144 - Guidelines on Security and Privacy in 


\section{Public Cloud Computing.}

NIST_800-146. (2012). SP 800-146 - Cloud Computing Synopsis and Recommendations.

RAMOS, Anderson.; et al. Security Officer 1: Guia Oficial para Formação de Gestores em Segurança da Informação. São Paulo: Zouk, 2006.

REVISTA INFO. As lixeiras do mundo desenvolvido. Ed.302. São Paulo: EDITORA ABRIL, 2011.

SILVA, Carlo M. R.; et al. (2013). Security Threats in Cloud Computing Models: Domains and Proposals. CLOUD 2013, v. 6, p. x, 2013.

VAQUERO, L. M. et al. (2011). Locking the sky: A survey on laaS cloud security. Springer Journal Computer. V. 91, I. 1, p. 93-118.

VERAS, Manoel. Cloud Computing - Nova Arquitetura da TI. Rio de Janeiro: Brasport, 2012.

TRIGUEIRO, André. Mundo sustentável: abrindo espaço na mídia para um planeta em transformação. Disponível em:

<http://books.google.com.br/books?id=JGuWT7mLVgUC\&pg=PA66\&dq=reciclagem +de+computadores\&hl=pt-

BR\&ei=yskVTub1OKLd0QGrzsBB\&sa=X\&oi=book_result\&ct=result\&resnum=1\&ved $=0 C E A Q 6 A E w A A \# v=$ onepage $\& q=$ reciclagem $\% 20$ de $\% 20$ computadores $\& f=f a l s e>$.

Acessado em 10/06/2011

WU, L.; BUYYA, R. (2010). Technical Report CLOUDS-TR-2010-5, Cloud Computing and Distributed Systems Laboratory, The University of Melbourne, Australia. 